\title{
Adenomatoid odontogenic tumor of the maxilla mimicking a dentigerous cyst
}

\section{Pseudogruczołowy guz zębopochodny szczęki przypominający torbiel zawiązkową}

\author{
Wojciech Pawlak ${ }^{1, B, C, E, F}$, Zdzisław Woźniak ${ }^{2, B, C}$, Kamil Nelke $e^{3, A, B, D-F}$ \\ 1 Department of Maxillofacial Surgery, Wroclaw Medical University, Wrocław, Poland \\ 2 Department of Pathology, Wroclaw Medical University, Wrocław, Poland \\ ${ }^{3}$ University Teaching Hospital in Wroclaw, Wrocław, Poland \\ A - research concept and design; $B$ - collection and/or assembly of data; $C$ - data analysis and interpretation; \\ $D$ - writing the article; $E$ - critical revision of the article; $F$ - final approval of article
}

Address for correspondence

Kamil Nelke

E-mail: kamil.nelke@gmail.com

Funding sources

none declared

Conflict of interest

none declared

Received on February 11, 2017

Revised on April 05, 2017

Accepted on May 20, 2017

\begin{abstract}
Adenomatoid odontogenic tumor (AOT) is a rare benign tumor which originates in the odontogenic epithelium. Some theories indicate its glandular origin because of the incidence in the same embryological pouch. This form of odontogenic tumor rarely metastasizes and generally only requires regional excisional biopsy within healthy tissues. The tumor is commonly associated with an unerupted tooth, mimicking a dentigerous cyst. A0Ts are usually located in the anterior portion of the maxilla and are seen more frequently in young female patients and occur in the second decade of life. These are mostly asymptomatic small lesions discovered incidentally on panoramic radiograph; however, when a bacterial co-infection is present, their diagnosis can be troublesome. Treatment is conservative enucleation and curettage. In most cases recurrences are rare.
\end{abstract}

Due to the rare occurrence of this lesion and its clinical features, the authors described a case of AOT in a 15-year old female presenting as a cystic mass associated with unerupted maxillary anterior teeth.

Key words: treatment outcomes, dentigerous cyst, maxilla, adenomatoid odontogenic tumor, odontogenic tumor

Słowa kluczowe: wyniki leczenia, torbiel zawiązkowa, szczęka, pseudogruczołowy guz zębopochodny, guz zębopochodny
DOI

10.17219/dmp/73904

Copyright

() 2017 by Wroclaw Medical University

and Polish Dental Society

This is an article distributed under the terms of the

Creative Commons Attribution Non-Commercial License

(http://creativecommons.org/licenses/by-nc-nd/4.0/) 
Adenomatoid odontogenic tumor (AOT) is a rare benign odontogenic lesion that accounts for only $3 \%$ of all odontogenic tumors. ${ }^{1}$ The lesion was known by many names, including adenoameloblastoma, adenomatoid ameloblastoma, ameloblastic adenomatoid tumour and adenoameloblastic odontoma. Nowadays, AOT nomenclature is well known, and was established by WHO in $1971 .^{2}$

The AOT often presents as a painless swelling of the anterior region of the maxilla and is commonly associated with an unerupted tooth, mimicking a dentigerous cyst. ${ }^{3}$

AOTs are seen more frequently in young female patients and occur in the second decade of life. The tumor is asymptomatic, and small lesions are discovered incidentally on X-ray examinations. When treatment consists of conservative enucleation and curettage, recurrences are rare. ${ }^{4,5}$ We describe the occurrence and treatment of AOT in the anterior region of the maxilla associated with upper teeth impaction.

\section{Case report}

A 15-year-old female patient was referred by her orthodontist because of painless and slowly increasing swelling on labial aspect of right maxillary alveolus. Three years earlier she was diagnosed with a vertical impaction of the permanent upper right lateral incisor and a canine with prolonged retention of the upper right deciduous canine. Radiographically, a cyst-like appearance was present around the lateral projection of the crown and $2 / 3$ of the lateral part of the root of the embedded maxillary right lateral incisor. There was slight enlargement of pericoronal radiolucency associated with the impacted maxillary right canine (Fig. 1). A dentigerous cyst associated with embedded tooth 12 was the initial diagnosis.

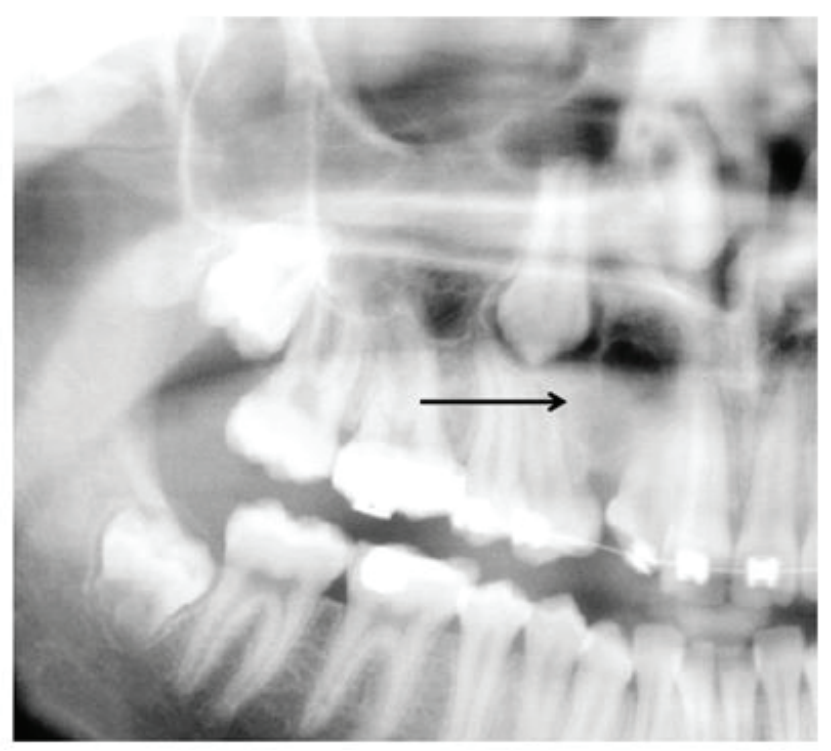

Fig. 1. Detail from preoperative pantomographic $X$-ray reveals circumscribed radiolucent area in relation to teeth 11 to 14 and embedded tooth 13

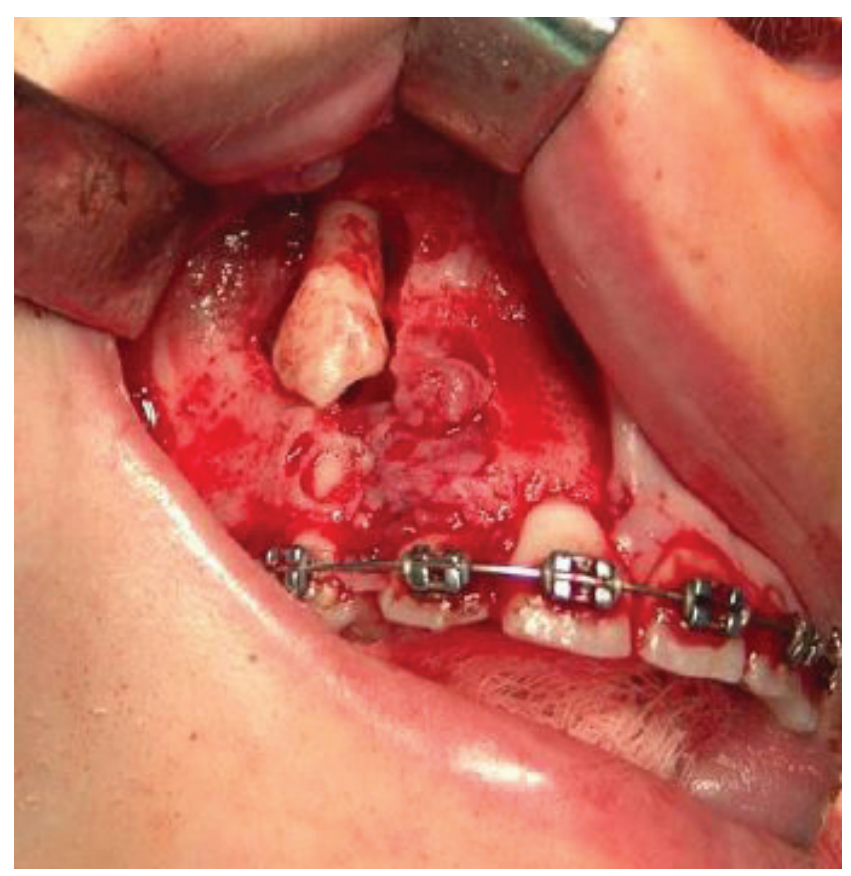

Fig. 2. Intraoperative photograph - after removal of destructed cortical bone, a tumor and impacted tooth 13 were exposed

Upon examination, swelling was seen on labial aspect of right maxillary alveolar bone in area related to teeth 11 to 14. Swelling was hard and non-tender to palpation, and covered with a normal mucosa. All upper teeth related to the lesion reacted positively to the thermal pulp testing. Panoramic X-ray showed circumscribed radiolucent area in relation to teeth 11 to 14 and impaction of the right upper canine.

Under general anesthesia a mucoperiosteal flap from the right upper central incisor to the right upper first molar was reflected to expose the labial aspect of the tumor. The labial cortex over the lateral incisor was very thin, expanded, and had areas of bone resorption (Fig. 2). After the destructed cortical bone was removed, a soft consistency and reddish color tumor was exposed and removed along with the impacted upper right permanent canine.

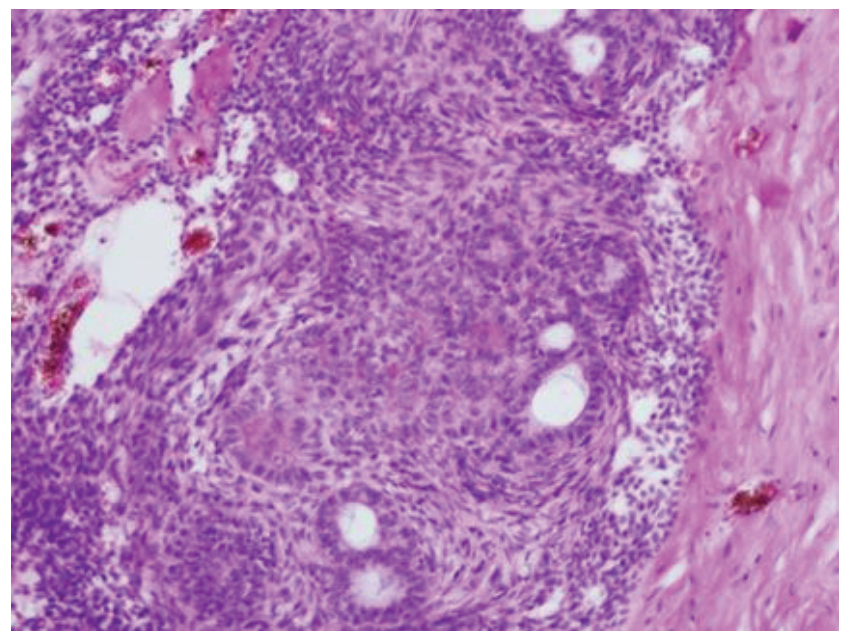

Fig. 3. Adenomatoid odontogenic tumor in H-E staining, magn. $\times 200$ with characteristic odontogenic epithelium with duct-like structures 
The area was curetted well, leaving a wide moat-like intrabony defect. The flap was placed in its original position and sutured. Healing was uneventful. After 2 years of follow-up no recurrence was present.

Pathohistological features of AOT include various forms of characteristic duct-like structures within the connective tissue (Fig. 3). Most cases are cystic, same as in the presented case; however, rare solid lesions can also be found. Immunohistological findings revealed that cytokeratin profile of AOT is very much alike as a follicular cyst, and most often positive for staining with CK5, CK17 and CK19. ${ }^{4-6}$

\section{Discussion}

Adenomatoid odontogenic tumor, regarded by many as hamartoma, is a relatively rare tumor that comprises only $0.1 \%$ of tumors and cysts of the jaws, and 3\% of all odontogenic tumors of epithelial origin. ${ }^{7}$ The AOT is a slowly growing lesion, located most frequently in the anterior maxilla (2: 1 ratio in relation to mandible), and is seen more frequently in young females with a ratio of $1.4: 1$ to $3: 1$ patients in the second decade of life. ${ }^{6,8}$

Presented tumors are rarely seen in the maxilla with relation to impacted incisors or canine. A study conducted by Anegundi et al. ${ }^{9}$ confirms our findings that AOT related with impacted canine is an extremely rare case, perhaps related with mixed dentition, teeth eruption and formation process.

There are 3 histopathological variants of AOT, namely follicular, extrafollicular and peripheral, all having identical histology. ${ }^{10}$ A type of adenomatoid odontogenic cyst (AOC) was also reported. Cemento-ossifying fibroma (COF) might be misdiagnosed with AOT because of a similarity in the type of calcifying lesion. Differential diagnosis should also have in mind the presence of calcifying epithelial odontogenic tumors (CEOT) or their mixed/hybrid form like AOT/CEOT. ${ }^{11}$

The follicular and extrafollicular variants are both intraosseous and account for approximately $96 \%$ of all AOTs, of which $71 \%$ are of follicular type. The follicular type is associated with an embedded tooth, while the extrafollicular variant has no relation with an impacted tooth. ${ }^{12}$ The rare peripheral variant occurs in the gingival tissue of tooth-bearing areas and is rarely detected radiographically.

The AOT is usually associated with unerupted teeth, and permanent canines and lateral incisors. More posterior lesions involving premolars and molars are quite rare. ${ }^{13}$ Radiographically AOT is a well-defined unilocular lesion surrounding the crown of the unerupted tooth, often misdiagnosed with dentigerous cyst. Chindasombatjaroen et al. performed a study to describe radiological features of AOT and calcifying cystic odontogenic tumors (CCOT) and concluded that radiolucency is more common in
AOT than in CCOT. ${ }^{14}$ Radiological root resorption is rare. However Saluja et al. suggests that root resorption might be a potential symptom of its aggressiveness. ${ }^{15}$

Some AOTs produce calcifications that appear on the radiograph as "snow-flake" densities. The patient we describe in this report presented radiographically radiolucency surrounding the crown and extending apically beyond the cementoenamel junction of the embedded maxillary lateral incisor. The multilocular appearance might be highly bound with its aggressiveness. ${ }^{16}$ It is hypothesized that AOT is a benign odontogenic tumor which develops from the enamel organ, dental lamina, reduced enamel epithelium or their remnants. While ameloblastomas are aggressive, AOT is a more hamartomatous lesion with different tumorigenesis and clinical findings. $\beta$-catenin is not so common in AOT as much as in ameloblastomas, similarly to the MDM2 (monoclonal antibody, Murine Double Minute). ${ }^{17}$

Clinical and radiological features might be troublesome for an inexperienced clinician. Its demanding histopathological features require careful examination from every pathologist.

Enucleation and curettage are the treatments of choice for AOT and recurrences are extremely rare. Discovery of AOT in our patient who was undergoing orthodontic treatment is not surprising because the age at which AOTs are most often found coincides with the age at which many young patients are treated orthodontically. These patients usually have progressive pantomographic $\mathrm{X}$-rays taken, which can reveal this asymptomatic bone lesion.

\section{Conclusions}

AOT in the anterior part of the maxilla related to the impacted tooth is a rare finding. Differential diagnosis should consider various lesions. We conclude that mixed dentition might be an imported factor in the occurrence of AOT; however, other studies need to be performed.

\section{References}

1. Carr R, Foster B, Gilliam C, Evans G. Odontogenic adenomatoid tumors associated with orthodontic treatment. Am J Orthod Dentofacial Orthop. 1995;107:648-650.

2. Laheji A, Sakharde S, Chidambaram S, Gondhalekar RR, Shankar U, Radhika A. Adenoameloblastoma: a dilemma in diagnosis. J Contemp Dent Pract. 2012;13:925-929.

3. Sharma N, Passi S, Kumar VV. Adenomatoid odontogenic tumor. As an unusual mandibular manifestation. Contemp Clin Dent. 2012;3:29-32.

4. Swasdison S, Dhanuthai K, Jainkittivong A, Philipsen H. Adenomatoid odontogenic tumors: An analysis of 67 cases in a Thai population. Oral Surg Oral Med Oral Pathol Oral Radiol Endod. 2008;105:210-215.

5. Mohamed A, Singh AS, Raubenheimer EJ, Bouckaert MMR. Adenomatoid odontogenic tumour: Review of the literature and an analysis of 33 cases from South Africa. Int J Oral Maxillofac Surg. 2010;39:843-846. 
6. Garg D, Palaskar S, Shetty V, Bhushan A. Adenomatoid odontogenic tumor - hamartoma or true neoplasm: A case report. J Oral Sci. 2009:51:155-159.

7. Arotiba G, Arotiba J, Olaitan A, Ajayi O. The adenomatoid odontogenic tumor: an analysis of 57 cases in Black African population. J Oral Maxillofac Surg. 1997;55:146-148.

8. Toida M, Hyodo I, Okuda T, Tatematsu N. Adenomatoid odontogenic tumor: Report of two cases and survey of 126 cases in Japan. J Oral Maxillofac Surg. 1992;50:282-285.

9. Anegundi RT, Radhika R, Patil S, Sahana BA. Adenomatoid odontogenic tumor: an uncommon location. Pediatr Dent. 2011;33:437-439.

10. Kurra S, Gunupati S, Prasad PR, Raju YS, Reddy BV. An adenomatoid odontogenic cyst (AOC) with an assorted histoarchitecture: A unique entity. J Clin Diagn Res. 2013;7:1232-1235.

11. de Matos FR, Nonaka CF, Pinto LP, de Souza LB, de Almeida Freitas R. Adenomatoid odontogenic tumor: Retrospective study of 15 cases with emphasis on histopathologic features. Head Neck Pathol. 2012;6:430-437.

12. Angiero F, Crippa R. Adenomatoid odontogenic tumor: A case report with immunohistological profile. Anticancer Res. 2013;33:2673-2677.

13. Lee JS, Yoon SJ, Kang BC, Kim OJ, Kim YH. Adenomatoid odontogenic tumor associated with unerupted first primary molar. Pediatr Dent. 2012;34:493-495.

14. Chindasombatjaroen J, Poomsawat S, Kakimoto N, Shimamoto H. Calcifying cystic odontogenic tumor and adenomatoid odontogenic tumor: Radiographic evaluation. Oral Surg Oral Med Oral Pathol Oral Radiol. 2012;114:796-803.

15. Saluja R, Kaur G, Singh P. Aggressive adenomatoid odontogenic tumor of mandible showing root resorption: A histological case report. Dent Res J. (Isfahan) 2013;10:279-282.

16. Narayanan VS, Naidu G, Ragavendra R, Mhaske-Jedhe S, Haldar M. Adenomatoid odontogenic tumor of the mandible with unusual radiographic features: A case report. Imaging Sci Dent. 2013:43:111-115.

17. Harnet JC, Pedeutour F, Raybaud H, Ambrosetti D, Fabas T, Lombardi T. Immunohistological features in adenomatoid odontogenic tumor: Review of the literature and first expression and mutational analysis of $\beta$-catenin in this unusual lesion of the jaws. J Oral Maxillofac Surg. 2013;71:706-713. 